\title{
Inverse Correlation between Stress and Adaptive Coping in Medical Students
}

\author{
Zafar Rasheed ${ }^{1 *}$, Ali Shariq ${ }^{2}$, Abdulmonem Alsalhi $^{3}$, Saleh Almesned $^{3}$, Saud Alhussain $^{3}$, Ahmed Alshammari $^{3}$, Mazen Almatrudi ${ }^{3}$, \\ Saif Alshammari ${ }^{3}$, Sulaiman Alkhuzayyim ${ }^{3}$, Abdullah Alkhamiss $^{3}$, Muslet H. Alharbi ${ }^{4}$, Waleed Al Abdulmonem ${ }^{3}$ \\ ${ }^{1}$ Department of Medical Biochemistry, College of Medicine, Qassim University, Buraidah, Saudi Arabia; ${ }^{2}$ Department of \\ Microbiology, College of Medicine, Qassim University, Buraidah, Saudi Arabia; ${ }^{3}$ Department of Pathology, College of Medicine, \\ Qassim University, Buraidah, Saudi Arabia; ${ }^{4}$ Department of Family Medicine, College of Medicine, Qassim University, Buraidah, \\ Saudi Arabia
}

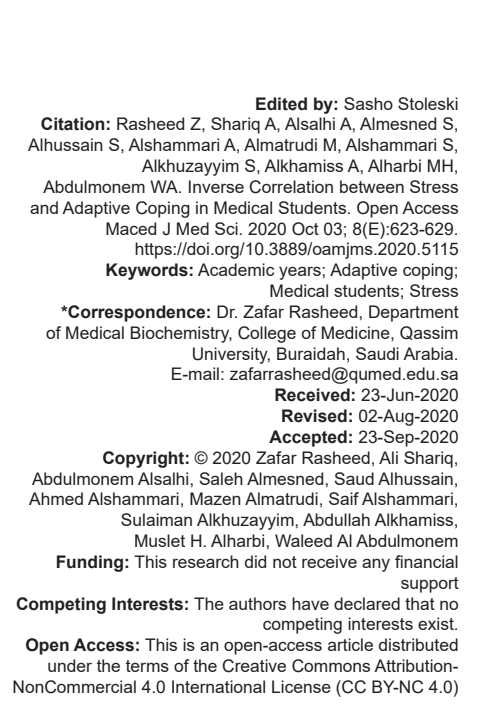

\section{Abstract}

BACKGROUND: Medical students in their academic years are generally under stress but very few studies revealed the relationship between the stress and how the students manage to adapt these stressful conditions.

AIM: The aim of the study was to investigate the levels of stress and their adaptive coping in the $1^{\text {st }} 3$ years medical students and also to determine the factors associated with adaptive coping strategies.

METHODS: This is a descriptive cross-sectional study conducted on 441 medical students of Qassim University from September-October 2019. First 3 years medical students were randomly selected and their stress levels or adaptive coping strategies were determined by general health questionnaire (GHQ-12) and strategies coping mechanisms (SCM), respectively. The 5-points Likert scale was used for scoring and the data obtained were further validated by DASS and Brief COPE scales.

RESULTS: Out of 441 medical students, $39.2 \%$ agreed to participate. The data showed that the level of stress among students was highest during their $1^{\text {st }}$ year academic blocks, followed by $2^{\text {nd }}$ and $3^{\text {rd }}$ year students. Interesting the adaptive coping among them was found highest during the academic blocks of $3^{\text {rd }}$ year students, followed by the $2^{\text {nd }}$ and $1^{\text {st }}$ year students. Importantly, female students showed better adaptation against stress. Students living with their parents avoided stress in better ways as compared to those who were living alone.

CONCLUSION: This is the first study that shows an inverse correlation between the stress and adaptive coping in medical students of Qassim University. The data concluded that adaptation of stress in the $3^{\text {rd }}$-year students was the highest followed by $2^{\text {nd }}$ and $1^{\text {st }}$ year medical students. Moreover, female students adapted well against stress and students living alone showed worse adaptation of stress.

\section{Introduction}

Attending a medical school is considered as a very challenging experience as it changes the complete lifestyle of the medical students. There is a general perception that the academic years in medical schools are stressful but very few studies were reported to reveal the relationship between stress and how medical students manage to adapt to these new stressful conditions [1], [2], [3]. Adaptation in terms of medical education is basically a constantly altering process that trails exposure to innovative life circumstances, with the individuals' social environment manipulating [4]. In the Kingdom of Saudi Arabia, 5 academic years are mandatory to be graduated in any of the medical schools. In the first 3 academic years, students are taught basic medical science subjects and in the last 2 years students are exposed to clinical teaching along with attending real patients under the supervision of well experienced medical professionals [5]. Attending the $1^{\text {st }}$ year of medical college is a very challenging for a student as it is utmost precarious for college adaptation because of the massive imaginable adjustment troubles [1], [2], [6]. A good quality $1^{\text {st }}$ year transition encompasses a medical student to efficiently function in remaining years by acquiring the skill to deal with a new and multifarious world of medical science [2], [6]. Studies have shown that a large number of students in their $1^{\text {st }}$ academic years were quit from their medical school [1], [2], [7]. The major reason(s) for students quitting were innovative complex goals, weak commitment, and lack of time management and absence of external motivation [6], [7]. A study conducted in a local public university of Malaysia revealed four important factors that resulted in a weak adaptation of medical students to the medical education environment were health problems, academic difficulties, financial crunch, social, and personal glitches [8]. Recently, another study conducted in Ukraine stated that the failure in the adaptation of $1^{\text {st }}$-year students in their medical schools seriously affected, not only on their educational activities but also on their social and 
personal independence [9]. Recently, it was reported that every year more than 100,000 students were registered in medical schools globally but by the end of their $1^{\text {st }}$ year more than $50 \%$ were dropped out [1], [2], [3]. This clearly explained the difficulties of medical students in their transition from senior secondary school to medical school. In support of these observations, a number of studies were conducted to estimate the stress levels among medical students as compared to non-medical students and a majority of them pointed out that medical students were in more stress as compared to other college students [7], [8]. Specifically, stress was also reported among the $1^{\text {st }}$ year medical students of Qassim University, similar to the medical students of other universities [10], [11], [12]. Despite these difficulties facing by the medical students just after transition from senior secondary school to medical college, only few studies were conducted on the stress and its associated adaptive behavior [11], [12] but none of them showed a correlation between the stress levels and their adaptive coping strategies and also none was conducted on medical students of Qassim University. In view of these, this study was designed for the first time to find out the correlation between the level of stress and its adaptive coping among first 3 years medical students of Qassim University and the factors associated with adaptive coping against the stress were also attempted.

\section{Methods}

\section{Study type, design, and participants}

This is a descriptive cross-sectional study performed on medical students of Qassim University from September to October 2019. The first 3 years medical students from Qassim University were randomly selected and were involved in the study. The study was designed to compare the stress levels and the adaptive coping on first 3 years undergraduate medical students.

\section{Data collection and instruments}

The data were collected using self-administered questionnaires, which comprised three main sections: The first section was on the social demographic details, the second section was a general health questionnaire (GHQ-12) comprised the questions on general health to measure stress levels as described previously [8], [13] and the third section of the questionnaire was comprised of questions on the strategies coping mechanisms (SCM) such as problem solving, positive reinterpretation and expression of emotion, facilitate student adaptation against stress, mental well-being, and physical health [14]. The validity and reliability of the questionnaire used in this study were previously approved by a number of studies [8], [13], [14]. The Likert 5-points scale was used for data scoring, point 1 on the scale represents strongly disagree, points $2,3,4$, and 5 represent mildly disagree, neutral, mildly agree, and strongly agree, respectively, as described previously [15]. The data related to stress obtained by the Likert 5-points scale were further validated by the Depression Anxiety Stress Scales (DASS) [16], [17]. The DASS scale was a wellestablished and a well-validated method for measuring of depression, anxiety, and stress but here we used only "the stress section" of DASS, which comprised 14 questions about difficulty, relaxing, nervous arousal, and being easily upset/agitated, irritable/over-reactive and impatient as described previously [16], [17]. Whereas the data on the adaptive coping strategies were further validated by another well-validated scale Brief COPE, which comprised 13 questions on the adaptive coping strategies of focusing on problems and emotions as described previously [18], [19].

\section{Ethical consideration}

Ethical approval of this study was taken from the Qassim University and written informed consents from the participated medical students were administered from the questionnaires used for their health assessment.

\section{Statistical analysis}

The data were statistically analyzed by the Student t-test or ANOVA followed by Tukey's post hoc and/or Bonferroni post hoc tests using one-way and/or two-way analysis for statistical comparison between the groups. $p<0.05$ was considered significant.

\section{Results}

Out of 441 medical students, 173 were responded completely; therefore, we have included them in this study. Among them $26.6 \%$ students were $1^{\text {st }}$ year medical students, whereas $31.8 \%$ and $41.6 \%$ were $2^{\text {nd }}$ and $3^{\text {rd }}$ years students, respectively. All demographic details are summarized in Table 1. In this study, we first compared the levels of stress among $1^{\text {st }}$ 3 years medical students with their adaptive coping potential by the 5-points Likert scale. The 5-points Likert scale data for measuring the stress levels in first, second, and third medical students were found to be 3.8, 2.6, and 1.7, respectively (Figure 1a). The data clearly pointed out the highest degree of stress in $1^{\text {st }}$ year medical students followed by $2^{\text {nd }}$ year students, whereas the $3^{\text {rd }}$ year medical students showed lower stress levels $(p<0.05)$. At the same time, the same the 5-points Likert scale was also used for measuring the levels of adaptive coping among the same groups of 
medical students. As shown in Figure 1b, the 5-points Likert scale shows that the reading for adaptive coping in $1^{\text {st }}$ year, $2^{\text {nd }}$ year, and $3^{\text {rd }}$ year was $1.7,2.5$, and 3.9 , respectively. The data clearly pointed out the $3^{\text {rd }}$ year students were more stress adaptive as compared to the $1^{\text {st }}$ year and $2^{\text {nd }}$ year students $(p<0.05)$.

Table 1: Socio-demographic profile of the medical students

\begin{tabular}{ll}
\hline Socio-demographic factor & No. $(\%)$ \\
\hline Nationality & Saudi national \\
Gender & \\
Male & $94(54.3)$ \\
Female & $79(45.7)$ \\
Residence & $68(39.3)$ \\
$\quad$ Living without parents & $105(66.7)$ \\
$\quad$ Home with parents & \\
Academic year & $46(26.6)$ \\
$\quad$ First medical students & $55(31.8)$ \\
Second medical students & $72(41.6)$ \\
Third medical students & \\
\hline
\end{tabular}

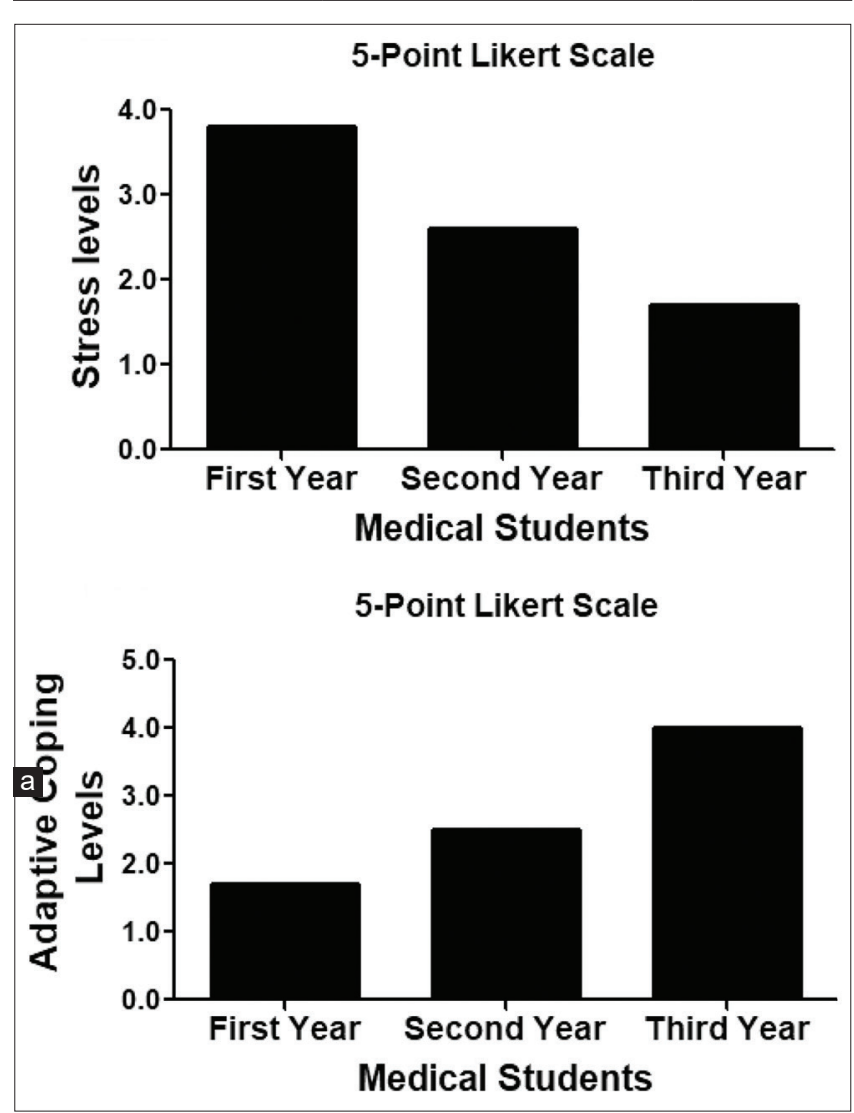

Figure 1: Levels of stress (a) and adaptation coping (b) among $1^{\text {st }}$ year, $2^{\text {nd }}$ year, and $3^{\text {rd }}$ year medical students. Levels of stress and adaptive coping were measured by 5-point Likert scale

To analyze the data in depth, we analyzed the levels of stress and adaptive coping of medical students b their academic blocks. As shown in Figure 2a, level of stress among $1^{\text {st }}$ year medical students during their all academic blocks were found to be highest followed by the academic blocks of during the $2^{\text {nd }}$ and $3^{\text {rd }}$ years $(p<0.05)$. Specifically, the 5-points Likert scale data for $1^{\text {st }}$ year academic blocks, medical education (ME), man and his environment and metabolism (MEM), growth and development (GD), principle of diseases (PD), and musculoskeletal and skin (MSS) blocks were found to be $3.7,3.9,3.8,4.0$, and 3.8 , respectively. Whereas the 5-points Likert scale data for the $2^{\text {nd }}$ year students' blocks, endocrine block (EB), hematopoietic and
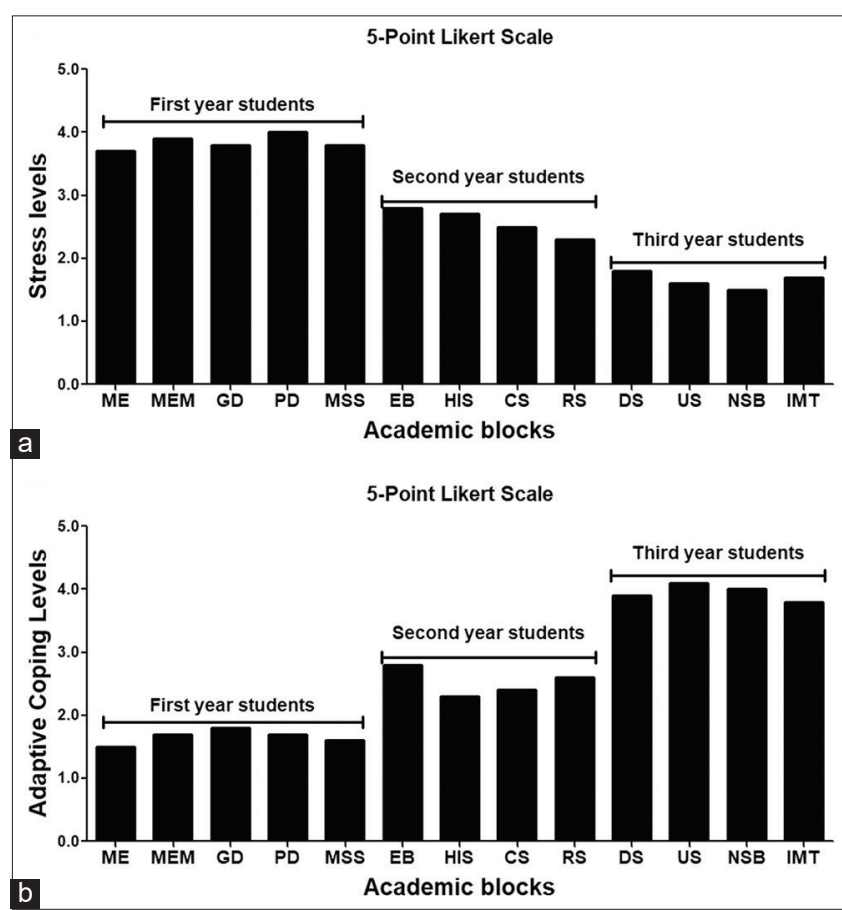

Figure 2: Levels of stress (a) and adaptation coping (b) among $1^{\text {st }}$ year, $2^{\text {nd }}$ year, and $3^{\text {rd }}$ year medical students during their academic blocks. Levels of stress and adaptive coping were measured by 5-point Likert scale. ME: Medical education block, MEM: Man and his environment and metabolism block, GD block: Growth and development block; $P D$ : Principle of diseases block, MSS: Musculoskeletal and skin block, EB: Endocrine block, HIS: Hematopoietic and immune system block, CS: Cardiovascular system block, RS: Respiratory system block, DS Digestive system block, US: Urinary system block, NSB: Nervous system-special senses-behavioral sciences block, IMT: Integrated multisystems and therapeutics block

immune system (HIS), cardiovascular system (CS), and respiratory system (RS) blocks were $2.8,2.7,2.5$, and 2.3 , respectively. The stress levels in the $3^{\text {rd }}$ year student blocks, the digestive system (DS), urinary system (US), nervous system - special senses - behavioral sciences (NSB), and integrated multisystems and therapeutics (IMT) blocks were found to be 1.8, 1.6, 1.5, and 1.7, respectively. The data clearly pointed out that stress level was significantly lower among the students of $3^{\text {rd }}$ year as compared with the $1^{\text {st }}$ year and $2^{\text {nd }}$ year medical students $(p<0.05)$. On the other hand, we have also demonstrated the adaptive coping of all year 3 years' students during their respective academic blocks $(p<0.05)$. The 5-points Likert scale data for $1^{\text {st }}$ year academic blocks, ME, MEM, GD, PD, and MSS were found to be $1.5,1.7,1.8,1.7$, and 1.6, respectively. Whereas the 5-points Likert scale data for the $2^{\text {nd }}$ year students blocks, EB, HIS, CS, and RS were 2.8, 2.3, 2.4 , and 2.6, respectively. The levels adaptive coping in $3^{\text {rd }}$ year student during their blocks, DS, US, NSB, and IMT were found to be 3.9, 4.1, 4.0, and 3.8, respectively (Figure 2b). The 5-points Likert scale data for stress levels and the levels of adaptive coping were completely reserved in the $1^{\text {st }}$ and $3^{\text {rd }}$ years medical students during their respective blocks. Interestingly, the 5-points Likert scale data of stress levels and the adaptive coping were 
almost the same for $2^{\text {nd }}$ year students during their blocks $(p>0.05)$, indicating that $2^{\text {nd }}$ year students moderately under stress but they were also moderately coping the stress (Figure 2). The data clearly pointed out that stress level was significantly low among the students of $3^{\text {rd }}$ year as compared with the $1^{\text {st }}$ year and $2^{\text {nd }}$ year medical students $(p<0.05)$. To determine the factors associated with the level of stress and its adaptive coping among the studied students, the data for male and female students were separately analyzed. In this study, $54.3 \%$ were male students whereas as $45.7 \%$ were females. The 5-points Likert scale data for measuring the stress levels in male and female students were found to be 3.3 and 2.5, respectively (Figure 3a). Moreover, the adaptive coping potentials of studied male and female students were 2.2 and 3.9, respectively (Figure 3b). These results clearly pointed out that female medical student were better than males to handle the stress during their medical education $(p<0.05)$. To determine more factors associated with stress and coping, we determined the comparison between those students which were living alone with those, which were living with their families. The 5-points Likert scale data for measuring the stress levels in students living alone and students living with their families were found to be 3.7 and 1.3, respectively (Figure 4a). Moreover, the adaptive coping potentials of students living alone and students living with their families were 1.4 and 3.9 , respectively (Figure 4b). These results clearly indicated that students living alone were more disturbed as compared with the

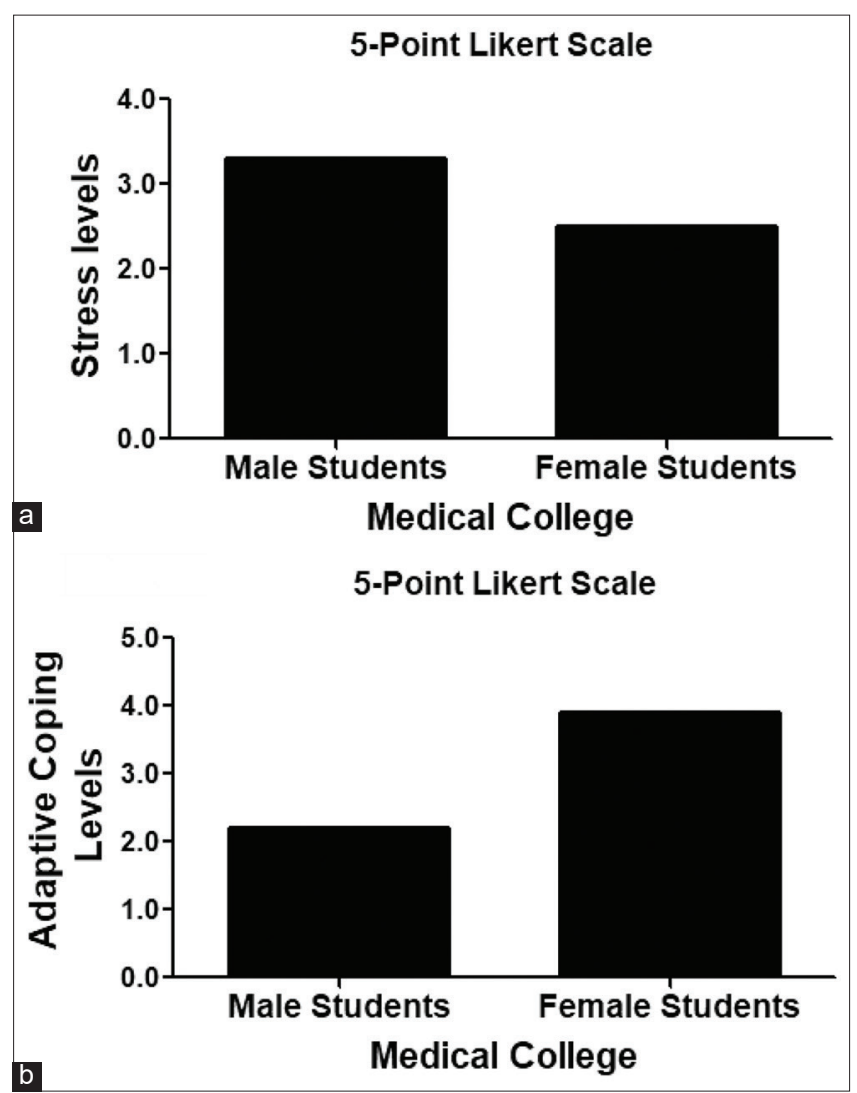

Figure 3: Levels of stress (a) and adaptation coping (b) among male and female medical students. Levels of stress and adaptive coping were measured by 5-point Likert scale students living with their families ( $p<0.05$ ). Not only have these, results also pointed out that students living with their families were more stress adaptive as compared with those medical students which were living alone $(p<0.05)$.

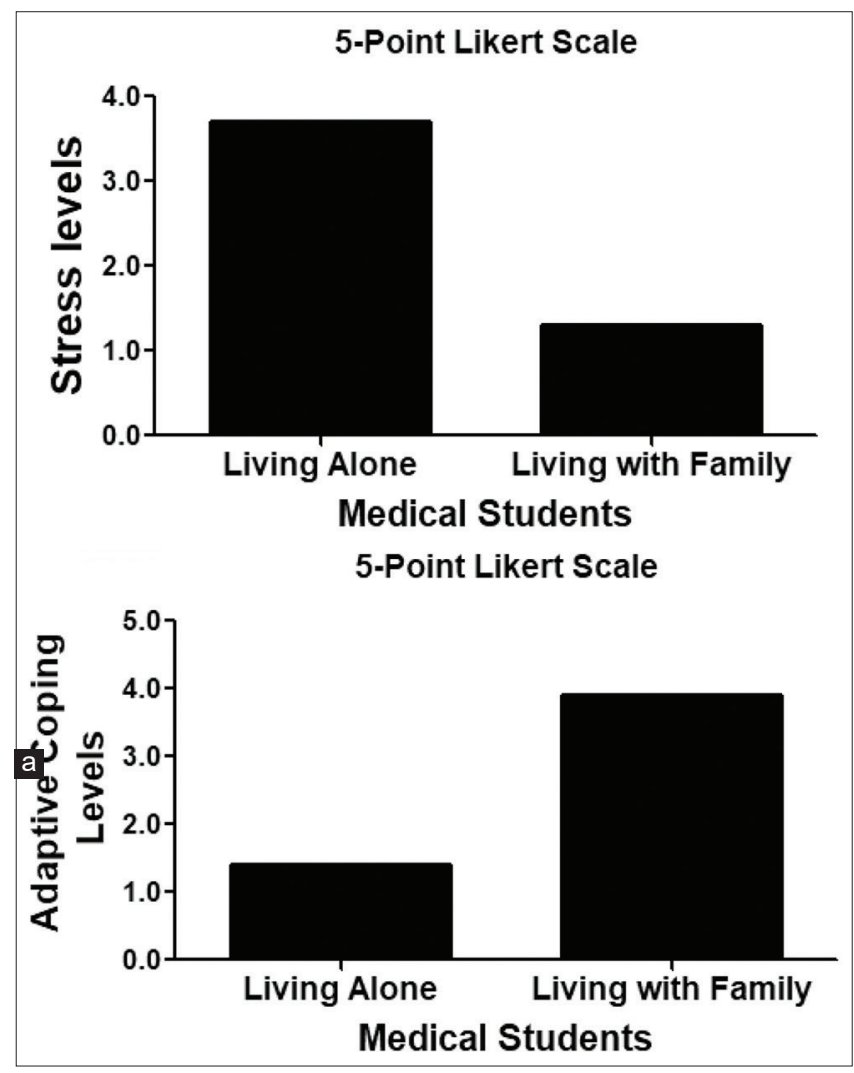

Figure 4: Levels of stress (a) and adaptation coping (b) among medical students living alone and living with their families. Levels of stress and adaptive coping were measured by 5-point Likert scale

The data obtained by the Likert scale on stress and adaptive coping in medical students were brther validated by DASS and Brief COPE scales, respectively. The DASS measurement of stress in $1^{\text {st }}$, $2^{\text {nd }}$, and $3^{\text {rd }}$ years students showed that stress level was highest in $1^{\text {st }}$ year students, followed by $2^{\text {nd }}$ and $3^{\text {rd }}$ years students. As the normality among $1^{\text {st }}$ year students was only $17.4 \%$, whereas the normality level in $2^{\text {nd }}$ year and $3^{\text {rd }}$ year students was significantly higher by $27.3 \%$ and $40.3 \%$, respectively ( $p<0.05$ ). Specifically, severe stress levels and extremely severe stress levels were also found highest in $1^{\text {st }}$ year students and lowest in $3^{\text {rd }}$ year students $(p<0.05)$. The complete details of all stress levels including mild, moderate, severe, and extremely severe in all studied groups of students are summarized in Table 2. On the other hand, brief COPE measurements showed that the problem focused strategies such as active coping, positive reframing, planning, use of instrument support, and acceptance scores were highest in $3^{\text {rd }}$ year students and lowest in $1^{\text {st }}$ year students $(p<0.05)$, whereas $2^{\text {nd }}$ year students showed moderate scored of these problem focused strategies. Not only have these, we also determined emotionally focused strategies such as self-destruction, behavioral disengagements, venting, substance use, 
religion, self-blamed, humor, and denial in the studied groups of students.

Table 2: Levels of stress in $1^{\text {st }}, 2^{\text {nd }}$, and $3^{\text {rd }}$ year medical students. Stress levels were measured by DASS scale

\begin{tabular}{|c|c|c|c|c|c|c|}
\hline \multirow[t]{2}{*}{ Stress levels } & \multicolumn{2}{|c|}{$1^{\text {st }}$ year, $n=46$} & \multicolumn{2}{|c|}{$2^{\text {nd }}$ year, $n=55$} & \multicolumn{2}{|c|}{$3^{\text {rd }}$ year, $n=72$} \\
\hline & $\mathrm{n}$ & Percent & $\mathrm{n}$ & Percent & $\mathrm{n}$ & Percent \\
\hline Normal & 08 & 17.4 & 15 & 27.3 & 29 & $40.3^{\#}$ \\
\hline Mild stressed & 02 & 04.3 & 10 & 18.2 & 23 & $31.9^{\mathrm{F \#}}$ \\
\hline Moderate stressed & 08 & 17.4 & 18 & 32.7 & 13 & 18.0 \\
\hline Severe stressed & 18 & $39.1^{*}$ & 09 & 16.4 & 04 & 05.5 \\
\hline Extremely severe Stressed & 10 & $21.7^{\star *}$ & 03 & 05.4 & 03 & 04.2 \\
\hline
\end{tabular}

First year students scored highest for all these emotionally focused strategies, followed by $2^{\text {nd }}$ and $3^{\text {rd }}$ year students. The complete description of the data obtained by Brief COPE scale in $1^{\text {st }}, 2^{\text {nd }}$, and $3^{\text {rd }}$ years medical students is summarized in Table 3.

Table 3: Adaptive coping strategies of $1^{\text {st }}, 2^{\text {nd }}$, and $3^{\text {rd }}$ year medical students. Adaptive coping of the students was measured by Brief COPE scale

\begin{tabular}{|c|c|c|c|c|c|c|}
\hline \multirow[t]{2}{*}{ Adaptive coping strategy } & \multicolumn{2}{|c|}{$1^{\text {st }}$ year, $n=46$} & \multicolumn{2}{|c|}{$2^{\text {nd }}$ year, $n=55$} & \multicolumn{2}{|c|}{$3^{\text {rd }}$ year, $n=72$} \\
\hline & Mean & SD & Mean & SD & Mean & SD \\
\hline \multicolumn{7}{|l|}{ Problem focused } \\
\hline Active coping & 5.6 & 1.82 & 6.03 & 1.57 & 6.31 & $1.47^{\#}$ \\
\hline Positive reframing & 5.8 & 1.32 & 6.11 & 1.41 & 6.41 & $1.82^{\#}$ \\
\hline Planning & 4.87 & 1.71 & 5.51 & 1.71 & 6.09 & $1.81^{\#}$ \\
\hline Use of instrument support & 5.19 & 1.83 & 5.24 & 1.82 & 5.92 & $1.32^{\#}$ \\
\hline Acceptance & 5.31 & 1.48 & 5.92 & 1.47 & 6.19 & $1.32^{\#}$ \\
\hline \multicolumn{7}{|l|}{ Emotionally focused } \\
\hline Self-destruction & 6.39 & $1.28^{*}$ & 6.12 & 1.43 & 5.97 & 1.39 \\
\hline Behavioral disengagements & 4.89 & $1.32^{*}$ & 4.32 & 1.41 & 3.96 & 1.82 \\
\hline Venting & 5.41 & 1.72 & 5.28 & 1.82 & 5.01 & 1.38 \\
\hline Substance use & 2.82 & 1.64 & 2.51 & 1.32 & 2.04 & 1.21 \\
\hline Religion & 6.05 & $1.83^{*}$ & 5.05 & 1.82 & 4.98 & 1.81 \\
\hline Self-blamed & 5.81 & $1.82^{*}$ & 4.71 & 1.31 & 4.02 & 1.42 \\
\hline Humor & 5.37 & 1.82 & 5.15 & 1.73 & 4.96 & 1.81 \\
\hline Denial & 4.29 & $1.41^{*}$ & 4.01 & 1.21 & 3.81 & 1.71 \\
\hline
\end{tabular}

, number of sus: ${ }^{*} p<0,05$ versus $3^{\text {rd }}$ year students.

\section{Discussion}

This is the first comprehensive study performed on medical students of Qassim University that showed an inverse correlation between the level of stress and its adaptive coping among first 3 years medical students. For the past two or three decades, it has been continuously reporting that the study at medical school is highly stressful as compared to the studies in non-medical schools [3], [20] and dropout rate of $1^{\text {st }}$ year medical was considerably high as compared with the dropout rate of non-medical students [12]. As an example, a study conducted on Omam Medical students showed the dropout rate in $1^{\text {st }}$ year students was $20 \%$ [21]. Similarly, several other studies have also shown moderate to severe levels of stress among medical students but extremely severe stress was reported in the $1^{\text {st }}$ year just after transition from secondary school [1], [2], [3]. Furthermore, studies in multi-ethnic settings also showed that depression, anxiety, and stress among medical students [22]. In this study, we first compared the levels of stress among $1^{\text {st }} 3$ year medical students and then their adaptive coping potential were measured by a validated and reliable questionnaire [8], [13], [14] and the scoring of the data was performed using the 5-points Likert scale. The 5-points Likert scale showed the highest degree of stress in $1^{\text {st }}$ year medical students followed by $2^{\text {nd }}$ year students, whereas the $3^{\text {rd }}$ year medical students showed lower stress levels. At the same time, using the same 5-points Likert scale showed that the levels of adaptive coping among $3^{\text {rd }}$ year students were highest, followed by $2^{\text {nd }}$ and $1^{\text {st }}$ year students. These data on the $1^{\text {st }} 3$ years of medical students were further verified using other scales DASS and Brief COPE. Both DASS and Brief COPE scales were well standard scales, their validity and reliability were proved by a number of investigators in their studies for measuring stress and the potential adaptive coping strategies, respectively [16], [17], [18], [19]. To validate the data on stress, we used the stress section of DASS scale for measuring the stress levels in medical students. Again, the data showed the highest degree of stress levels in $1^{\text {st }}$ year medical students followed by $2^{\text {nd }}$ year students, whereas the $3^{\text {rd }}$ year medical students showed lower stress levels. In addition, the DASS scale also characterized the stress levels in medical students into mild, moderate, severe, and extremely severe and the data pointed out that most of the studied $1^{\text {st }}$ year medical students were under severe or extremely severe stressed, whereas most of the $3^{\text {rd }}$ year students showed mild stress or they were normal during their studies. These data again verified that the highest degree of stress was in $1^{\text {st }}$ year medical students, followed by $2^{\text {nd }}$ year students, whereas the $3^{\text {rd }}$ year medical students showed lower stress levels or they were normal. These data are in full agreement with the view that the $1^{\text {st }}$ year medical students were in more stress due to the transition from secondary school to medical school [23]. To verify the data of adaptive coping against the stress of medical students, the different adaptive coping strategies were applied using the Brief COPE scale. Our data showed that the scores of problem focused coping strategies such as active coping, positive reframing, planning, use of instrument support, and the levels of acceptance were highest in $3^{\text {rd }}$ year students, followed by the $2^{\text {nd }}$ year students. Whereas, the $1^{\text {st }}$ year medical students showed the lowest score for these problem focused coping strategies. These data are in full agreement with the view that active coping, positive reframing, planning, use of instrument support, and the levels of acceptance have a positive relation with wellbeing and negative with stress [18], [19], [24]. Thus, these coping strategies were considered as adaptive or functional strategies. These data were consistent with what were found by a number of investigators in their coping studies that pointed out that these problem focused coping strategies could be conceived as adaptive coping [18], [19], [24], [25]. Therefore, we highlighted these adaptive coping strategies which directly or indirectly contributed to the well-being of $3^{\text {rd }}$ year medical students as they scored highest points among all three medical students groups. On the other hand, the scores for the emotionally focused coping strategies such as self-destruction, behavioral disengagement, religion, selfblaming, and denial were highest in $1^{\text {st }}$ year students, 
followed by the $2^{\text {nd }}$ and $3^{\text {rd }}$ year medical students, clearly indicating that they have a negative relation with wellbeing and positive with stress. These data were also supported by the other studies conducted on different population groups [18], [26]. Therefore, these strategies are also considered as maladaptive or dysfunctional strategies as their highest scores were found in $1^{\text {st }}$ year students. These findings clearly indicated that $3^{\text {rd }}$ year medical students were having more potential to adapt coping against stress as compared to the $2^{\text {nd }}$ and $1^{\text {st }}$ year students. To study this fact in more detail, we analyzed the levels of stress and adaptive coping of medical students in their academic blocks. The data showed that the level of stress among $1^{\text {st }}$ year medical students during their all academic blocks was significantly more followed by the academic blocks of the $2^{\text {nd }}$ and $3^{\text {rd }}$ years. In contrast, the data demonstrated the adaptive coping was highest in $3^{\text {rd }}$ year students followed by $2^{\text {nd }}$ and $1^{\text {st }}$ year students. These results clearly indicated that the stress level and the level of adaptive coping were completely reserved in the $1^{\text {st }}$ and $3^{\text {rd }}$ year medical students during their respective blocks. Interestingly, the data of stress levels and the adaptive coping were almost the same for $2^{\text {nd }}$ year students during their blocks, indicating that $2^{\text {nd }}$ year students moderately under stress which was completely reversed by adaptive coping.

To investigate the factors associated with the level of stress and its adaptive coping among these students, the data for male and female students were separately analyzed. Results pointed out that the female medical students were better in adaptive coping against stress as of male students. These results are fully supported by the previous studies showing that male medical students were more in stress as compared with female students during their medical education [27]. Not only have these, we also determined the level of stress and its adaptive coping in those students which were living alone and their results were compared with those which were living with their parents. These results indicated that students living alone were disturbed and were less stress adaptive as compared with those students living with their families. These results are also supported by the findings that showed that the students received social support from their parents, relatives, and friends [28]. The studied medical students also reported that they received several types of support which include proper guidance and positive social interaction. These were the factors responsible for them to adopt coping against stress in a better way as compared with those students which were living without their parents.

\section{Conclusion}

This study showed that adaptation against stress among the $3^{\text {rd }}$-year students was the highest followed by $2^{\text {nd }}$ and $1^{\text {st }}$ year medical students. The data show that female students adapted well and students living alone showed worse adaptation against stress.

\section{Acknowledgment}

The authors gratefully acknowledged the support from the college administration for the data collection.

\section{Declarations}

\section{Ethics approval and consent to participate}

The ethical approval was taken from Qassim University. Written informed consents were taken from all participated medical students.

\section{Consent to publish}

N/A (data were collected via routine surveys).

\section{Availability of data and materials}

Available on request from the corresponding author.

\section{Funding}

No funding received.

\section{Authors' contributions}

All authors contributed to the conceptual setup of the study. ZR, AS, AAA, AA, MHA, and WA were involved in data analysis and manuscript drafting; $A A s$, SAm, SAh, MA, SAs, and SAk performed data collection.

\section{References}

1. Kiessling C, Schubert B, Scheffner D, Burger W. First year medical students' perceptions of stress and support: A comparison between reformed and traditional track curricula. Med Educ. 2004;38(5):504-9. https://doi. org/10.1046/j.1365-2929.2004.01816.x 


\section{PMid:15107084}

2. Juma FZ, Abas T, Banu S. The transition from high school to university: A medical student's perspective. Adv Med Educ Pract. 2016;7:517-8. https://doi.org/10.2147/amep.s114753 PMid:27672347

3. Hill MR, Goicochea S, Merlo LJ. In their own words: Stressors facing medical students in the millennial generation. Med Educ Online. 2018;23(1):1530558. https://doi.org/10.1080/10872981. 2018.1530558

PMid:30286698

4. Woodruff JN. Accounting for complexity in medical education A model of adaptive behaviour in medicine. Med Educ. 2019;53(9):861-73. https://doi.org/10.1111/medu.13905

\section{PMid:31106901}

5. Telmesani A, Zaini RG, Ghazi HO. Medical education in Saudi Arabia: A review of recent developments and future challenges. East Mediterr Health J. 2011;17(8):703-7. https:// doi.org/10.26719/2011.17.8.703

PMid:21977574

6. Schei E, Johnsrud RE, Mildestvedt T, Pedersen R, Hjörleifsson S. Trustingly bewildered. How first-year medical students make sense of their learning experience in a traditional, preclinical curriculum. Med Educ Online. 2018;23(1):1500344. https://doi. org/10.1080/10872981.2018.1500344

PMid:30064330

7. Glauser W. Why do students quit medical school far less often in Canada than in other countries? CMAJ. 2019;191(6):E174-5. https://doi.org/10.1503/cmaj.109-5704

PMid:30745406

8. Yusoff MS, Rahim AF, Yaacob MJ. Prevalence and sources of stress among Universiti Sains Malaysia medical students. Malays J Med Sci. 2010;17(1):30-7.

\section{PMid:22135523}

9. Katrushova L, Yalanska S, Rudenko L, Katrushov O. Peculiarities of the process of psychological adaptation of foreign students of Ukrainian higher education institutions of medical profile, role of emotional intelligence in the socialization process. Wiad Lek. 2019;72(10):1930-4. https://doi.org/10.36740/wlek201910114 PMid:31982016

10. Almogbel $\mathrm{E}$, Aladhadh AM, Almotyri BH, Alhumaid AF, Rasheed N. Stress associated alterations in dietary behaviours of undergraduate students of Qassim University, Saudi Arabia. Open Access Maced J Med Sci. 2019;7(13):2182-8. https://doi. org/10.3889/oamjms.2019.571 PMid:31456849

11. Inam SB. Anxiety and depression among students of a medical college in Saudi Arabia. Int J Health Sci (Qassim). 2007;1(2):295-300.

PMid:21475441

12. Heinen I, Bullinger M, Kocalevent RD. Perceived stress in first year medical students-associations with personal resources and emotional distress. BMC Med Educ. 2017;17(1):4. https:// doi.org/10.1186/s12909-016-0841-8 PMid:28056972

13. Montazeri A, Harirchi AM, Shariati M, Garmaroudi G, Ebadi M Fateh A. The 12-item general health questionnaire (GHQ-12): Translation and validation study of the Iranian version. Health Qual Life Outcomes. 2003;1:66. PMid:14614778

14. Fares J, Al Tabosh H, Saadeddin Z, El Mouhayyar C, Aridi H. Stress, burnout and coping strategies in preclinical medical students. N Am J Med Sci. 2016;8(2):75-81. https://doi. org/10.4103/1947-2714.177299

\section{PMid:27042604}

15. Cooper ID, Johnson TP. How to use survey results J Med Libr Assoc. 2016;104(2):174-7. https://doi. org/10.3163/1536-5050.104.2.016

PMid:27076809

16. Ahmed F, Al-Radhwan L, Al-Azmi G, Al-Beajan M. Association between stress and dietary behaviours among undergraduate students in Kuwait: Gender differences. J Nutr Health. 2014;1(1):1-8. https://doi.org/10.15744/2393-9060.1.104

17. Crawford JR, Henry JD. The depression anxiety stress scales (DASS): Normative data and latent structure in a large nonclinical sample. Br J Clin Psychol. 2003;2:111-31. https://doi. org/10.1348/014466503321903544 PMid:12828802

18. García FE, Barraza-Peña CG, Wlodarczyk A, AlvearCarrasco M, Reyes-Reyes A. Psychometric properties of the brief-COPE for the evaluation of coping strategies in the Chilean population. Psicol Reflex Crit. 2018;31(1):22. https:// doi.org/10.1186/s41155-018-0102-3

PMid:32026069

19. Meyer B. Coping with severe mental illness: Relations of the brief COPE with symptoms, functioning, and well-being. J Psychopathol Behav Assess 2001;23(4):265-77.

20. Abdulghani HM, AlKanhal AA, Mahmoud ES, Ponnamperuma GG, Alfaris EA. Stress and its effects on medical students: A cross-sectional study at a college of medicine in Saudi Arabia. J Health Popul Nutr. 2011;29(5):516-22. https:// doi.org/10.3329/jhpn.v29i5.8906

PMid:22106758

21. Al-Mahrooqi R, Denman CJ, Ateeq BA. Adaptation and firstyear university students in the sultanate of Oman. In: Issues in English Education in the Arab World. United Kingdom: Cambridge Scholars; 2015. p. 60-82.

22. Kulsoom B, Afsar NA. Stress, anxiety, and depression among medical students in a multiethnic setting. Neuropsychiatr Dis Treat. 2015;11:1713-22. https://doi.org/10.2147/ndt.s83577 PMid:26213470

23. Chong A. Habibah E, Rahil M, Jegak U. Adjustment amongst first year students in a Malaysian university. Eur J Soc Sci. 2009;8(3):21-9.

24. Urcuyo KR, Boyers AE, Carver CS, Antoni MH. Finding benefit in breast cancer: Relations with personality, coping, and concurrent well-being. Psychol Health. 2005;20(2):175-92. https://doi.org/10.1080/08870440512331317634

25. Yi-Frazier JP, Smith RE, Vitaliano PP, Yi JC, Mai S, Hillman M, et al. A person-focused analysis of resilience resources and coping in diabetes patients. Stress Health. 2010;26(1):51-60. https://doi.org/10.1002/smi.1258 PMid:20526415

26. Doron J, Trouillet R, Gana K, Boiché J, Neveu D, Ninot G. Examination of the hierarchical structure of the brief COPE in a French sample: Empirical and theoretical convergences. J Pers Assess. 2014;96(5):567-75. https://doi.org/10.1080/00223891.2 014.886255 PMid:24579758

27. Backović DV, Zivojinović JI, Maksimović J, Maksimović M Gender differences in academic stress and burnout among medical students in final years of education. Psychiatr Danub. 2012;24(2):175-81. https://doi.org/10.1201/9780429289989-22 PMid:22706416

28. Duma PT, Shawa LB. Including parents in inclusive practice: Supporting students with disabilities in higher education. Afr J Disabil. 2019;8:592. https://doi.org/10.4102/ajod.v8i0.592 PMid:31745462 